University of Wollongong

Research Online

Faculty of Business - Economics Working

Papers

Faculty of Business and Law

2010

\title{
An analysis of the world's environment and population dynamics with varying carrying capacity, concerns and skepticism
}

Peter Berck

University of California - Berkeley

Amnon Levy

University of Wollongong, levy@uow.edu.au

Khorshed Chowdhury

University of Wollongong, khorshed@uow.edu.au

Follow this and additional works at: https://ro.uow.edu.au/commwkpapers

\section{Recommended Citation}

Berck, Peter; Levy, Amnon; and Chowdhury, Khorshed, An analysis of the world's environment and population dynamics with varying carrying capacity, concerns and skepticism, Department of Economics, University of Wollongong, Working Paper 10-10, 2010, 30p.

https://ro.uow.edu.au/commwkpapers/226

Research Online is the open access institutional repository for the University of Wollongong. For further information contact the UOW Library: research-pubs@uow.edu.au 


\title{
University of Wollongong Economics Working Paper Series 2010
}

http://www.uow.edu.au/commerce/econ/wpapers.html

\section{An Analysis of the World's Environment and Population Dynamics with Varying Carrying Capacity, Concerns and Skepticism*}

\author{
Peter Berck \\ Department of Agricultural and Resource Economics \\ University of California, Berkeley \\ Berkeley, CA 94720, USA \\ E-mail: peter.berck@gmail.com \\ Amnon Levy \\ School of Economics \\ University of Wollongong \\ Wollongong, NSW 2522, Australia \\ E-mail: amnon levy@uow.edu.au \\ Khorshed Chowdhury \\ School of Economics \\ University of Wollongong \\ Wollongong, NSW 2522, Australia \\ E-mail: khorshed@uow.edu.au \\ School of Economics \\ University of Wollongong
}

WP 10-10

October 2010 


\title{
An Analysis of the World's Environment and Population Dynamics with Varying Carrying Capacity, Concerns and Skepticism*
}

\author{
Peter Berck \\ Department of Agricultural and Resource Economics \\ University of California, Berkeley \\ Berkeley, CA 94720, USA \\ E-mail: peter.berck@gmail.com \\ Amnon Levy \\ School of Economics \\ University of Wollongong \\ Wollongong, NSW 2522, Australia \\ E-mail: amnon_levy@uow.edu.au \\ Khorshed Chowdhury \\ School of Economics \\ University of Wollongong \\ Wollongong, NSW 2522, Australia \\ E-mail: khorshed@uow.edu.au
}

\begin{abstract}
Due to the open-access nature of the environment we consider an ad hoc adjustment of people's footprints to the quality of the environment. The adjustment is due to concerns, but hindered by skepticism about announced changes in the state of the environment. Changes in the quality of the environment affect Earth's carrying capacity. By expanding the Lotka-Volterra predator-prey model to include these features we show that despite skepticism the environment-population system does not collapse. We also show that in the ideal case of no skepticism, the interplay between the non-optimally changing environmental concerns and carrying capacity sends the world's environment and human population on an oscillating course that leads to a unique interior steady state. These results require no further technological, social or international progress.
\end{abstract}

Keywords: Environment; Population; Carrying Capacity; Concerns; Skepticism

*This working paper is a substantially revised version of an earlier working paper, 0916. Peter Berck and Amnon Levy, listed alphabetically, are fully and equally responsible for the development of this paper and its conceptual and empirical framework. Khorshed Chowdhury estimated the model's parameters. The authors are indebted to Jonathan Livermore for collecting the historical observations on background atmospheric carbon dioxide and human population and preparing the database. 


\section{Introduction}

Since the beginning of the industrial revolution the world's population has grown from less than a billion to almost seven billion. Accompanied by changes in per capita income, life-expectancy, preferences, technology and production scale and composition, this population growth has intensified the pressure on the natural environment and its resources. In turn, the environmental degradation has raised concerns for the state of the planet and its future suitability for life. Whether the conflict between the exploitation of the environment and concerns for the environment will be resolved in an uninhabitable planet has been debated since the publication of Thomas Robert Malthus' first essay on the principle of population in 1798. We contribute to this debate by constructing and analyzing a Lotka-Volterra (LV) type model of the joint dynamics of the population-environment system. In this system decreased environmental quality reduces the human population carrying capacity. In turn, deteriorating environmental quality can lead people to moderate their environmental footprint

Introduced by Lotka (1925) and Volterra (1931) the prototype L-V model is an ecologically isolated predator-prey system of differential equations where the predator population is the only agent controlling the prey and the prey population is the only source of food for the predators. In the context of human populations, variants of this prototype model have been recently used by Brander and Taylor (1998) to explain the growth and decline of an early civilization, whose essential renewable natural resources had been subject to open-access harvesting, and by Faria (2000) to speculate on the interaction between the populations of Homo Sapience Modern and Neanderthals. Our version includes logistic regeneration of the environment and population and takes the environment as limiting the carrying capacity for people and people's concerns for the environment as moderating environmental degradation. Both the number of people and people's choice on how much care to take of the environment, their environmental footprint, also determine the change in the environment. Earth's carrying capacity declines as the environment deteriorates and the intensity of the feedback is associated with the human population's aggregate level of environmental concerns. We regard people as reacting to environmental degradation by decreasing their individual exploitation of the environment, but in a non-optimal manner. We motivate this ad hoc approach with a brief literature review. 
In The Limits to Growth, Meadows et al. (1972) simulated a world where population, use of non-renewable resources and pollution grow exponentially while the ability of technology to increase the availability of food and manufactured goods is improving linearly. They explored the possibility of a sustainable feedback pattern that would be achieved by altering growth trends among the variables. One of their conclusions was that output-growth would be impeded by lack of resources, but if resources were not a binding constraint, then pollution would be. In the Dynamics of Growth in a Finite World, Meadows et al. (1974) have considered endogenous technological responses and simulated with an ad hoc model, World3, the effects of changing the delay between the perceived degradation and responses, and also changing the rate of technological progress. They have found that only under instant response and extreme technological progress can the population and economic system keep growing and avoid collapse. Anderies (2003) has considered a two-sector growth model for a (closed) developing economy where the agricultural sector uses and degrades the country's renewable natural capital, the birth rate increases with per capita agricultural output and diminishes with per capita manufacturing output, and the death rate diminishes with both types of per capita output. Using numerical bifurcation techniques and rescaling arguments he has come to the conclusion that demographic factors are relatively more important in preventing collapse of the natural resource base than technological factors. In our model, where changes in the size of the human population and the state of the environment are logistic and interrelated, collapse can be avoided even without technological progress and demographic transition as long as people are concerned and react to news about the state of the environment.

The rationale for a link between environmental degradation and prevention is a growing concern about the environment. Indeed, analyses of the Health of the Planet Survey, the World Values Survey and the International Social Survey Program indicate that, during the last twenty years, concern for the environment has not only intensified in rich countries, as advocated by the Affluence Hypothesis (Diekmann and Franzen, 1999; Franzen, 2003), but also in poor ones (Inglehart, 1995, 1997; Dunlap, Gallup and Gallup, 1993; Dunlap and Mertig, 1997). Supporting arguments and evidence of rising environmental concern are also presented in studies of the Environmental Kuznets Curve (Shafik and Bandyopadhyay, 1992; Selden and Song, 
1994; Grossman and Krueger, 1995; Andreoni and Levinson, 2001; Chavas, 2004; Carson, 2010).

In A Question of Balance, Nordhaus (2008) provides an integrated assessment model for global warming by elaborately incorporating cost-benefit aspects of abatement of greenhouse gas emissions into Ramsey's (1928) model of optimal economic growth. His DICE model has a feedback loop between the atmospheric carbon dioxide and abatement activities. With optimal aggregate feedback and the modest abatement costs estimated in the Intergovernmental Panel on Climate Change's Assessment Reports, environmental catastrophe is not predicted. However, as admitted by Nordhaus' (1992) use of expressions such as "idealized competitive markets" and "major leap of faith" (p. 7, second paragraph), optimal aggregate emission abatement is neither a market realization nor a likely outcome of international negotiations. In our model there is neither optimal, nor coordinated, adjustment of the human aggregate footprint on the environment. The underlying rationale is as follows.

The Earth's atmosphere and much of the contents of the Earth's surface and crust do not have the property of exclusivity: they belong to everyone and no one. Lack of exclusivity encourages free-riding in sharing the costs of abatement activities. The larger the costs of abatement activities are, the stronger is the inclination of individuals and countries to free-ride. As argued by Mendelsohn (2008), the full costs of abatement activities are not modest. Hence, the real system of the environment and human population does not have an optimal feedback nor, as revealed in the 2009 United Nations Climate Change Conference in Copenhagen, does it have a coordinated feedback.

In view of the absence of legally binding national and international commitments, we conduct a theoretical investigation of the possible implications of uncoordinated ad hoc individual responses for the joint course of the environment and human population and for survival. Our investigation is conducted within an analytically manageable dynamic model that highlights the interplay between carrying capacity and environmental concern in shaping the joint course of the environment and human population. We treat the whole biosphere as an open-access resource and construct, in Section 2, an L-V model of the environment and population system in which people modify their exploitation of the environment in accordance with their perception of the state of the environment. Our model incorporates the possibility of 
imperfect perceptions of the state of the environment due to skepticism about news on changes in the state of the environment. In section 3 our phase-plane analysis of a system plagued by skepticism suggests that, even in the absence of further technological, social and international progress, the environment-population system does not collapse and is likely to have an oscillating course. As demonstrated by section 4 , this course can be proven to be converging to an interior steady state in the case where people are not skeptical about the news on changes in the state of the environment and continually modify their perceptions of the environment from an accurate initial observation. Our estimations of the model's parameters in section 5 suggest that people's degree of skepticism about news on changes in the state of the environment is low and possibly zero. Section 6 sheds some light on the rational population growth and use of the environment by adding a maximization of utility from environmental amenities, social opportunities and consumption of goods to the formerly ad hoc L-V model of the environment and population.

\section{An L-V model of the environment and population}

The model comprises the motion equations of the physical environment and human population. In view of the objective of our investigation, these motion equations are taken to be deterministic — shocks (such as solar plasma bursts, volcanic eruptions, asteroid impact, nuclear accidents and epidemics) are ignored. While the size of Earth's physical environment is roughly fixed, the quality of Earth's environment (defined as the suitability of Earth's environment for human life) may vary over time. We denote Earth's quality adjusted physical environment at time $\mathrm{t}$ by $\mathrm{E}(\mathrm{t}) \geq 0$ and the population of human beings by $\mathrm{P}(\mathrm{t}) \geq 0$. As the regeneration functions of these variables are likely to be nonlinear and taken to be logistic, it is useful, from a technical point of view, to present the environment-population system in continuous time rather than discrete. The use of continuous time facilitates the analysis of the properties of non-linear dynamic systems. Our choice of continuous time modeling is also motivated by the nature of humans' breeding. Unlike most other species, humans breed continuously, leading to a population that has no clear age classes and frequent fluctuations. As discrete time only describes the very infrequent measurement of a continuous time phenomena, they can generate a prediction of significant swings in population over short periods of time. Human populations do not exhibit this see-saw pattern. 
The state of the environment is controlled by its natural regeneration, $\mathrm{G}_{\mathrm{e}}(\mathrm{t})$, and human exploitation. We assume that the physical environment is naturally regenerated as a logistic function of its current state. The regeneration function depends upon an intrinsic growth rate, $\mathrm{g}_{\mathrm{e}}$, and a maximal quality adjusted physical environment, $\mathrm{E}_{\max }$ :

$$
\mathrm{G}_{\mathrm{e}}(\mathrm{t})=\mathrm{g}_{\mathrm{e}} \mathrm{E}(\mathrm{t})\left(1-\frac{\mathrm{E}(\mathrm{t})}{\mathrm{E}_{\max }}\right) \text {. }
$$

People's exploitation of the environment, their aggregate footprint, depends both on their perception of the state of the environment $(\hat{E})$ and on the level of human population. When people believe that the environment is deteriorating, their concern for the state of the environment intensifies and, in turn, their individual footprints ( IFP) diminish. This reaction is represented by the following ad hoc behavioral feedback rule:

$$
\operatorname{IFP}(\mathrm{t})=\left(\frac{\beta}{1+\delta \mathrm{t}}\right) \hat{\mathrm{E}}(\mathrm{t}) .
$$

The numerator of the feedback coefficient, $\beta>0$, is negatively associated with people's degree of concern for the environment. The denominator of the feedback coefficient indicates the possibility of a time trend. This possibility is represented by a positive (negative) scalar $\delta$ if in the passage of time the effect of the individual's development and adoption of environmentally friendly technologies, products and activities is larger (smaller) than the effect of the individual's growing scale of production and consumption on the environment. Investment in education for environmental awareness can reduce $\beta$. Taxing environmentally harmful inputs and activities, or setting emissions trading schemes, can increase $\delta$.

Since there are $P$ people (identical, for tractability), each detracting IFP from the environmental stock, the change in the quality adjusted physical environment is

$$
\dot{\mathrm{E}}(\mathrm{t})=\mathrm{g}_{\mathrm{e}} \mathrm{E}(\mathrm{t})\left(1-\frac{\mathrm{E}(\mathrm{t})}{\mathrm{E}_{\max }}\right)-\left(\frac{\beta}{1+\delta \mathrm{t}}\right) \hat{\mathrm{E}}(\mathrm{t}) \mathrm{P}(\mathrm{t}) \text {. }
$$

In formulating the perceived state of the environment we consider the possibility of a systematic error stemming from skepticism. We assume that objectively measured changes in (rather than the state of) the environment are announced every instant. Skeptical people do not fully adjust their perception of the state of the environment to announced objectively measured intertemporal changes. 
Their partial adjustment is due to a less objective noise surrounding the objectively measured changes and an inclination to ignore a (time-wise) distant risk. We consider the possibility of a partial adjustment and let

$$
\dot{\hat{\mathrm{E}}}(\mathrm{t})=\psi \dot{\mathrm{E}}(\mathrm{t})
$$

where $0<\psi \leq 1$. The coefficient $0 \leq(1-\psi)<1$ represents people's degree of skepticism about announced objectively measured changes in the state of the environment. An alternative interpretation is that all of the measurements are obtained by unbiased, yet imperfect, procedures and hence are inherently inaccurate. No skepticism, absolute trust, is indicated by $\psi=1$. The degree of skepticism is positively related to the dispersion of the noise surrounding the objectively measured inter-temporal changes in the state of the environment. For example, if the noise is normally distributed around the accurately measured changes in state of the environment, $1-\psi$ may be interpreted as a product of the variance of the noise and the inclination to ignore a distant risk. We assume, for simplicity, that the distribution of the noise is stable and, consequently, take $\psi$ to be time-invariant.

By integrating both sides of equation (4) along the $(0, t)$ time interval,

$$
\hat{\mathrm{E}}(\mathrm{t})=\hat{\mathrm{E}}_{0}-\psi\left[\mathrm{E}_{0}-\mathrm{E}(\mathrm{t})\right] \text {. }
$$

Note that even when there is an undisrupted absolute trust, accurate perception of the state of the environment at $\mathrm{t}>0$ is not guaranteed as $\hat{E}(t)=E(t)+\left(\hat{E}_{0}-E_{0}\right)$. For the perception to be accurate, a perfect recording of the initial state of the environment in the human inter-temporal collective memory is also required (i.e., $\hat{\mathrm{E}}_{0}=\mathrm{E}_{0}$ ).

Next we turn to the equation describing population growth and its relation to the environment. Due to the fixed size of Earth's physical environment, a carrying capacity is incorporated into the formulation of the human population growth. Studies of wildlife population's survival and management typically employ growth functions embodying fixed, exogenously determined carrying capacity (Clark, 1976; Berck, 1979; Berck and Perloff, 1984; Horan and Bulte, 2004). Unlike wildlife, humans' impact on Earth's carrying capacity is significant. We assume that the more degraded the environment the less suitable Earth is for human life and that the human race irreversibly perishes when $E \leq E_{\text {ext }}$. We refer to $E_{\text {ext }}$ as the extinction threshold. At any point in time the physical environment's capacity to carry humans, $\hat{P}(t)$, rises 
with the current deviation of the quality adjusted physical environment from the extinction threshold. For instance, higher environmental quality in the form of lower greenhouse-gas concentrations results in higher potential food production. The carrying capacity is also influenced by technology, social security and services and international relations and cooperation, which we model as an exogenous function of time. For instance, peace, property rights, education and healthcare contribute to physical and human capital formation, production and marketing. Consequently, we specify the physical environment's capacity to carry humans as

$\hat{\mathrm{P}}(\mathrm{t})=(\alpha+\gamma \mathrm{t})\left[\mathrm{E}(\mathrm{t})-\mathrm{E}_{\text {ext }}\right]$

where $\alpha>0$ and $\gamma \geq 0$ are scalars. The term $(\alpha+\gamma \mathrm{t})>0$ is the ratio of the maximum sustainable human population to the level of the environment above the extinction threshold. A continuous overall technological, social and international progress is depicted by $\gamma>0$, whereas stagnation is represented by $\gamma=0$. Though not considered in this paper, $\gamma<0$ is possible. In particular, international relations might deteriorate to a destructive conflict that more than offsets the carrying-capacity gains from improvements in production technologies and healthcare services. The multiplicative specification reflects that, even in the presence of continuous combined progress, the carrying capacity of Earth might decline as the physical environment deteriorates and vanishes when the extinction threshold is reached. We assume that the world's population growth reacts to changes in Earth's carrying capacity and that the reaction can be approximated by a logistic function, $g_{p} P(t)[1-P(t) / P(t)]$. By incorporating the carrying-capacity equation (6) into this logistic growth function, the motion-equation of the human population is

$$
\dot{\mathrm{P}}(\mathrm{t})=\mathrm{g}_{\mathrm{p}} \mathrm{P}(\mathrm{t})\left(1-\frac{\mathrm{P}(\mathrm{t})}{(\alpha+\gamma \mathrm{t})\left[\mathrm{E}(\mathrm{t})-\mathrm{E}_{\text {ext }}\right]}\right)
$$

where $g_{p}$ is a positive scalar indicating the human population's intrinsic growth rate. ${ }^{1}$

\footnotetext{
${ }^{1}$ See Cohen (1996) for a critical review of projections of future human population size.
} 


\section{Does skepticism lead to collapse?}

Equations (3), (5) and (7) constitute a model of the environment and population. A continuous combined process of technological, healthcare, social and international relation change $(\gamma, \delta \neq 0)$ renders this equation-system non-autonomous. Such a multi-facet process precludes interior steady states. A priori, we do not know whether the multi-facet process is overall progressive or regressive. While technology can be expected to improve, social security and services and international relations and cooperation cannot.

Recalling that $\dot{\hat{\mathrm{E}}}(\mathrm{t})=\psi \dot{\mathrm{E}}(\mathrm{t})$, a deterioration of the environment $(\dot{\mathrm{E}}<0)$ lowers the perceived state of the environment and, subsequently, moderates the exploitation of the environment, but in a lower rate than the actual rate of deterioration of the environment. If the multi-facet process is overall regressive (i.e., $\gamma, \delta<0)$, the environment converges to an uninhabitable state $\left(\mathrm{E}_{\text {ext }}\right)$. The higher the degree of skepticism $(1-\psi)$ is the faster the convergence of the environment to a state of being uninhabitable. We ask whether collapse can be prevented by a multi-facet process that is overall non-regressive (i.e., $\gamma, \delta \geq 0$ ). We demonstrate that collapse is avoided even when the combined multi-facet process is neutral (i.e., $\gamma=0=\delta$ ) and the adjustment of footprints is impeded by skepticism.

With a neutral multi-facet process and skepticism $(0 \leq \psi<1)$, the system (3), (5) and (7) can be expressed as

$$
\begin{aligned}
& \dot{\mathrm{E}}(\mathrm{t})=\mathrm{g}_{\mathrm{e}} \mathrm{E}(\mathrm{t})\left(1-\frac{\mathrm{E}(\mathrm{t})}{\mathrm{E}_{\max }}\right)-\beta\left\{\hat{\mathrm{E}}_{0}-\psi\left[\mathrm{E}_{0}-\mathrm{E}(\mathrm{t})\right]\right\} \mathrm{P}(\mathrm{t}) \\
& \dot{\mathrm{P}}(\mathrm{t})=\mathrm{g}_{\mathrm{p}} \mathrm{P}(\mathrm{t})\left(1-\frac{\mathrm{P}(\mathrm{t})}{\alpha\left[\mathrm{E}(\mathrm{t})-\mathrm{E}_{\text {ext }}\right]}\right) .
\end{aligned}
$$

In steady-state, $\quad \mathrm{P}=\left[\mathrm{g}_{\mathrm{e}} \mathrm{E}\left(1-\mathrm{E} / \mathrm{E}_{\max }\right)\right] /\left\{\beta\left[\hat{\mathrm{E}}_{0}-\psi\left(\mathrm{E}_{0}-\mathrm{E}\right)\right]\right\} \quad$ and also $\mathrm{P}=\alpha\left[\mathrm{E}-\mathrm{E}_{\text {ext }}\right]$. In turn, the steady-state levels of the environment and population are:

$$
\begin{aligned}
\mathrm{E}_{1,2}^{\mathrm{ss}}= & \frac{\left[\mathrm{g}_{\mathrm{e}}+\alpha \beta\left(\psi \mathrm{E}_{\mathrm{ext}}+\psi \mathrm{E}_{0}-\hat{\mathrm{E}}_{0}\right)\right]}{2\left[\left(\mathrm{~g}_{\mathrm{e}} / \mathrm{E}_{\mathrm{max}}\right)+\alpha \beta \psi\right]} \\
& \pm \frac{\sqrt{\left[\mathrm{g}_{\mathrm{e}}+\alpha \beta\left(\psi \mathrm{E}_{\mathrm{ext}}+\psi \mathrm{E}_{0}-\hat{\mathrm{E}}_{0}\right)\right]^{2}+4\left[\left(\mathrm{~g}_{\mathrm{e}} / \mathrm{E}_{\max }\right)+\alpha \beta \psi\right] \alpha \beta\left(\hat{\mathrm{E}}_{0}-\psi \mathrm{E}_{0}\right) \mathrm{E}_{\mathrm{ext}}}}{2\left[\left(\mathrm{~g}_{\mathrm{e}} / \mathrm{E}_{\max }\right)+\alpha \beta \psi\right]}
\end{aligned}
$$

(see Appendix) and 
$\mathrm{P}_{1,2}^{\mathrm{ss}}=\alpha\left[\mathrm{E}_{1,2}^{\mathrm{ss}}-\mathrm{E}_{\mathrm{ext}}\right]$

An inspection of the discriminant in equation (10) reveals that if $\hat{\mathrm{E}}_{0} \geq \psi \mathrm{E}_{0}$, which is the likely case (either due to $\hat{\mathrm{E}}_{0} \geq \mathrm{E}_{0}$ or a significant degree of skepticism), there exists only one interior steady state. This property is clearly visible in the case of complete skepticism $(\psi=0)$ where the second term on the right-hand side of equation (10) exceeds the first. In that case,

$$
\mathrm{E}^{\mathrm{ss}}=\frac{\mathrm{E}_{\max }}{2 \mathrm{~g}_{\mathrm{e}}}\left[\left(\mathrm{g}_{\mathrm{e}}-\alpha \beta \hat{\mathrm{E}}_{0}\right)+\sqrt{\left(\mathrm{g}_{\mathrm{e}}-\alpha \beta \hat{\mathrm{E}}_{0}\right)^{2}+4 \mathrm{~g}_{\mathrm{e}} \alpha \beta \hat{\mathrm{E}}_{0} \mathrm{E}_{\mathrm{ext}} / \mathrm{E}_{\max }}\right] .
$$

In analyzing the nature of the interior steady state we note that $\mathrm{P}=\left[\mathrm{g}_{\mathrm{e}} \mathrm{E}\left(1-\mathrm{E} / \mathrm{E}_{\max }\right)\right] /\left\{\beta\left[\hat{\mathrm{E}}_{0}-\psi\left(\mathrm{E}_{0}-\mathrm{E}\right)\right]\right\} \quad$ defines the isocline $\dot{E}=0$ and $\mathrm{P}=\alpha\left[\mathrm{E}-\mathrm{E}_{\text {ext }}\right]$ the isocline $\dot{P}=0$. While the latter is depicted in the E-P plane by a positively sloped line, the slope of the isocline $\dot{E}=0$ is

$$
\frac{\mathrm{dP}}{\mathrm{dE}}=\frac{\mathrm{g}_{\mathrm{e}}\left\{\left(1-2 \mathrm{E} / \mathrm{E}_{\max }\right)\left[\hat{\mathrm{E}}_{0}-\psi\left(\mathrm{E}_{0}-\mathrm{E}\right)\right]-\psi \mathrm{E}\left(1-\mathrm{E} / \mathrm{E}_{\max }\right)\right\}}{\beta\left[\hat{\mathrm{E}}_{0}-\psi\left(\mathrm{E}_{0}-\mathrm{E}\right)\right]^{2}}\left\{\begin{array}{l}
>0 \text { for } 0 \leq \mathrm{E}<\tilde{\mathrm{E}} \\
=0 \text { for } \mathrm{E}=\tilde{\mathrm{E}} \\
<0 \text { for } \tilde{\mathrm{E}}<\mathrm{E} \leq \mathrm{E}_{\max }
\end{array}\right.
$$

as long as $\hat{\mathrm{E}}_{0}>\psi\left(\mathrm{E}_{0}-\mathrm{E}\right)$. The isoclines and the unique interior steady state are displayed in Figure 1 for this likely case. From equation (8), d $\dot{\mathrm{E}} / \mathrm{dP}<0$ and hence the horizontal arrow are leftward (rightward) pointed above (below) the isocline $\dot{E}=0$. From equation (9), $\mathrm{dP} / \mathrm{dE}>0$ and hence the vertical arrows are upward (downward) pointed in the phase to the right (left) of the isocline $\dot{\mathrm{P}}=0$.

The phase-plane diagram includes a dotted vertical line at $E=E_{\text {ext }}$. The combinations of the horizontal and vertical arrows identify a singular potential danger zone. We see that $\mathrm{E}$ potentially reaches $\mathrm{E}_{\mathrm{ext}}$ in quadrant $\mathrm{I}$. However, we show that if $\mathrm{E}$ begins above $\mathrm{E}_{\text {ext }}$ it never reaches $\mathrm{E}_{\mathrm{ext}}$. We have drawn a square of size $\varepsilon$ along the dotted line and cornered on a possible population-environment path in that quadrant. For $E$ to reach $E_{\text {ext }}$ it must hit the left side of such a square rather than exit through the bottom of the square. We consider $\varepsilon=\mathrm{E}(\mathrm{t})-\mathrm{E}_{\text {ext }}$. So in equation (9) we can, by the choice of $\varepsilon$, make $\dot{\mathrm{P}}$ arbitrarily negative with $\lim _{\varepsilon \rightarrow 0} \dot{\mathrm{P}} / \mathrm{P}=-\infty$. Equation (8) for $\dot{\mathrm{E}}$ is bounded from below when $\varepsilon$ approaches zero, which presumes that E approaches $\mathrm{E}_{\text {ext. }}$ The limiting value is 


$$
\dot{\mathrm{E}}=\mathrm{g}_{\mathrm{e}} \mathrm{E}_{\mathrm{ext}}\left(1-\frac{\mathrm{E}_{\mathrm{ext}}}{\mathrm{E}_{\text {max }}}\right)-\beta\left[\hat{\mathrm{E}}_{0}-\psi\left(\mathrm{E}_{0}-\mathrm{E}_{\mathrm{ext}}\right)\right] \mathrm{P}
$$

and it is bounded from below for every t. By choosing $\varepsilon$ sufficiently small, $\dot{\mathrm{P}}<\dot{\mathrm{E}}<0$ everywhere within the square. Hence the path moves faster downward than to the left and covers the distance $\varepsilon$ downward before it can cover that distance to the left. Therefore, the path exits the square through the bottom without hitting its left-hand side. This rules out $\mathrm{E}$ falling to the level of $\mathrm{E}_{\text {ext. }}$. Since population extinction can only happen in phase I and on, or below, $\mathrm{E}_{\mathrm{ext}}$ (see the arrows in the phase-plane diagram), population extinction cannot occur in our model, despite the adverse effect of skepticism and possibly overstated perception of the initial state of the environment on the adjustment of the population footprint.

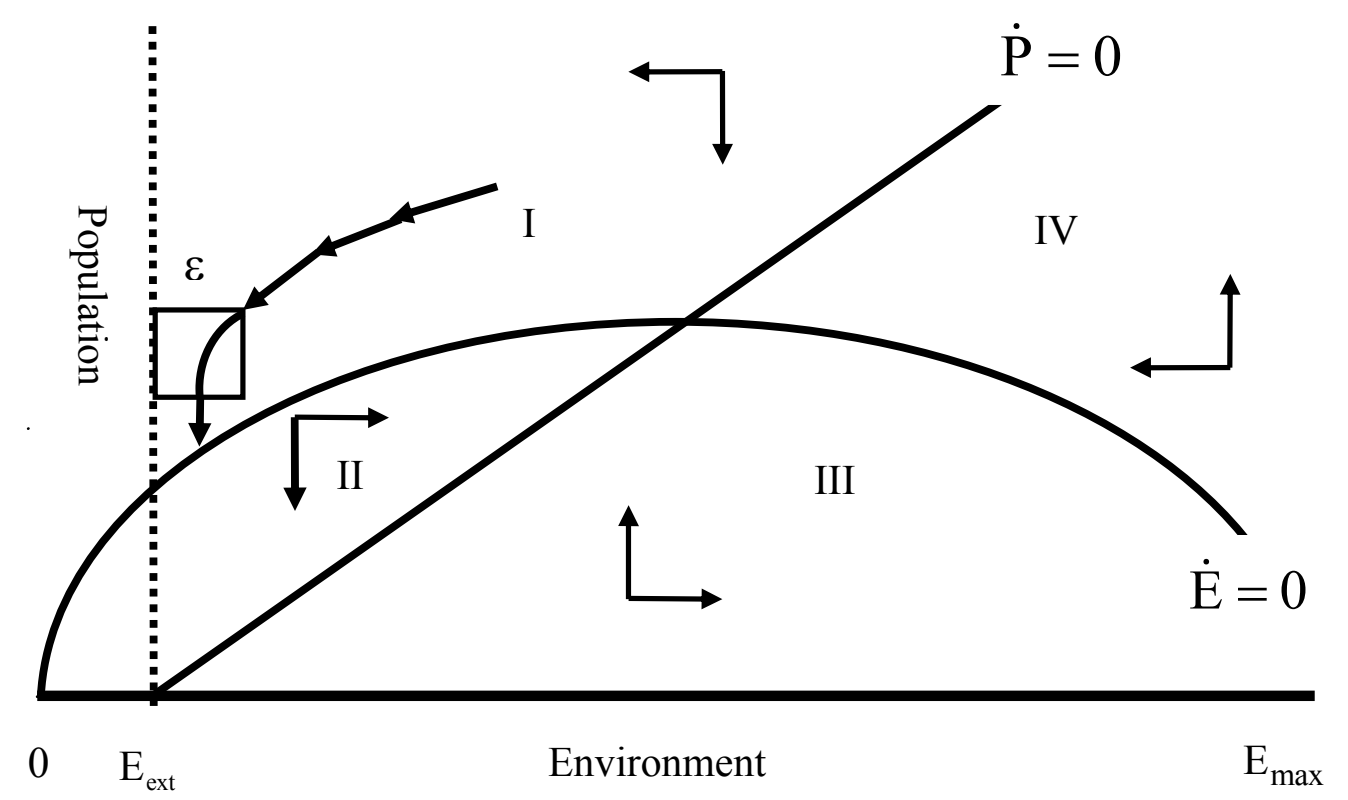

Figure 1. Phase-plane diagram for a system with skepticism

The combinations of the horizontal and vertical arrows in Figure 1 may also indicate a cyclical path of the environment and the population. This, however, cannot be formally established by inspecting the Jacobian of the system (8) and (9) evaluated in steady state (see Appendix): 


$$
\mathrm{J}=\left[\begin{array}{lc}
{\left[\mathrm{g}_{\mathrm{e}}\left(1-2 \mathrm{E}^{\mathrm{ss}} / \mathrm{E}_{\max }\right)-\beta \psi \alpha\left(\mathrm{E}^{\mathrm{sS}}-\mathrm{E}_{\mathrm{ext}}\right)\right]} & -\frac{\mathrm{g}_{\mathrm{e}} \mathrm{E}\left(1-\mathrm{E}^{\mathrm{ss}} / \mathrm{E}_{\max }\right)}{\alpha\left(\mathrm{E}^{\mathrm{ss}}-\mathrm{E}_{\mathrm{ext}}\right)} \\
\alpha \mathrm{g}_{\mathrm{p}} & -\mathrm{g}_{\mathrm{p}}
\end{array}\right] .
$$

We can only argue that if the joint path of the environment and population is indeed cyclical, it converges to the steady state if $\operatorname{tr} \mathrm{J}<0$; namely, as long as

$$
\mathrm{E}^{\mathrm{ss}}>\frac{\left(\mathrm{g}_{\mathrm{e}}-\mathrm{g}_{\mathrm{p}}\right)+\beta \psi \alpha \mathrm{E}_{\mathrm{ext}}}{2 \mathrm{~g}_{\mathrm{e}} / \mathrm{E}_{\max }+\beta \psi \alpha} .
$$

A formal investigation of the possibility of convergence to an interior steady state is only conclusive in the ideal case where changes in the environment are accurately measured and reported and also trusted by the public.

\section{Does trust facilitate convergence to interior steady state?}

As can be seen from equation (5), in the absence of skepticism $(\psi=1)$ and with an accurately recorded initial observation $\left(\hat{\mathrm{E}}_{0}=\mathrm{E}_{0}\right)$ and subsequent changes in the state of the environment and with a neutral multi-facet process $(\gamma=0=\delta)$, the environment-population equation system (3), (5) and (7) can be compressed and displayed as a system of two autonomous differential equations:

$$
\dot{\mathrm{E}}(\mathrm{t})=\mathrm{g}_{\mathrm{e}} \mathrm{E}(\mathrm{t})\left(1-\frac{\mathrm{E}(\mathrm{t})}{\mathrm{E}_{\max }}\right)-\beta \mathrm{E}(\mathrm{t}) \mathrm{P}(\mathrm{t})
$$

and

$$
\dot{\mathrm{P}}(\mathrm{t})=\mathrm{g}_{\mathrm{p}} \mathrm{P}(\mathrm{t})\left(1-\frac{\mathrm{P}(\mathrm{t})}{\alpha\left[\mathrm{E}(\mathrm{t})-\mathrm{E}_{\mathrm{ext}}\right]}\right) .
$$

The steady state of this system and its properties are identified in the ensuing sub sections.

\subsection{Unique, interior steady State}

The isocline $\dot{\mathrm{E}}=0$ is given by $\mathrm{E}=\mathrm{E}_{\max }-\left[\left(\beta \mathrm{E}_{\max }\right) / \mathrm{g}_{\mathrm{e}}\right] \mathrm{P}$ and the isocline $\dot{\mathrm{P}}=0$ by $\mathrm{E}=\mathrm{E}_{\text {ext }}+(1 / \alpha) \mathrm{P}$. Since the intercept of the negatively sloped isocline $\dot{\mathrm{E}}=0$ is larger than the intercept of the positively sloped isocline $\dot{\mathrm{P}}=0$ the intersection point of these linear isoclines is in the positive orthant of the $\mathrm{P}-\mathrm{E}$ plane. Namely, in the absence of skepticism and technological, healthcare, social and international progress, 
or regression, the environment-population system has a unique, interior steady state. The steady-state quality adjusted physical environment is

$$
\mathrm{E}^{*}=\mathrm{E}_{\mathrm{ext}}+\frac{1}{\alpha}\left(\frac{\mathrm{E}_{\max }-\mathrm{E}_{\mathrm{ext}}}{\frac{1}{\alpha}+\frac{\beta}{\mathrm{g}_{\mathrm{e}} / \mathrm{E}_{\max }}}\right)
$$

and the steady-state human population is

$$
\mathrm{P}^{*}=\frac{\mathrm{E}_{\max }-\mathrm{E}_{\mathrm{ext}}}{\frac{1}{\alpha}+\frac{\beta}{\mathrm{g}_{\mathrm{e}} / \mathrm{E}_{\max }}} .
$$

Equations (19) and (20) suggest that the steady-state quality adjusted physical environment is higher than the extinction threshold $\left(\mathrm{E}_{\mathrm{ext}}\right)$ and, consequently, the stationary human population is not nil. These equations also suggest that the stationary population and the steady-state quality adjusted physical environment increase with the environment's intrinsic recovery rate $\left(g_{e}\right)$ and the maximal quality adjusted physical environment $\left(\mathrm{E}_{\max }\right)$, and decrease with the footprint's feedback coefficient $(\beta)$. The steady-state population also decreases with the extinction threshold $\left(\mathrm{E}_{\mathrm{ext}}\right)$. The steady-state population further decreases with the stock of the quality adjusted extra (beyond $\mathrm{E}_{\text {ext }}$ ) environmental resources required for sustaining a human being under perpetual stagnation $(1 / \alpha)$. As the subsequent positive effect of the population decline on the stationary quality of the environment can be dominated by the larger per capita requirement of environmental stock, $\partial\left(\mathrm{E}^{*}-\mathrm{E}_{\mathrm{ext}}\right) / \partial(1 / \alpha)=\left\{1-1 /\left[1 / \alpha+\beta \mathrm{E}_{\max } / \mathrm{g}_{\mathrm{e}}\right]\right\} \mathrm{P}^{*}$ is not necessarily positive.

\subsection{Local convergence}

We argue that changing carrying capacity and environmental concerns are likely to engender a cyclical environment-population course that converges to the steady state. The underlying rationale is as follows. With the quality of the environment being initially high, excess carrying capacity is large and concerns for the environment are low. Hence, population grows rapidly and so also does its aggregate footprint. As the environment deteriorates the excess carrying capacity diminishes and, in turn, population growth decelerates. At the same time, concerns for the environment rise. Negative population growth and rising concerns moderate the aggregate footprint and, 
subsequently, the environment starts improving. As the environment gradually improves, carrying capacity is slightly increased. Population growth is resumed and is accompanied for a while by moderated concerns. Then, with a bit larger aggregate footprint the environment slightly deteriorates, population growth diminishes and concerns rise, and so on, with gradual convergence to steady state.

A formal identification of the joint course of the environment and human population in the neighborhood of the steady state requires an evaluation of the Jacobian of the motion-equations (17) and (18) in the steady state indicated by (19) and $(20){ }^{2}$

$\tilde{\mathbf{J}}=\left[\begin{array}{cc}\partial \dot{\mathrm{E}}(*) / \partial \mathrm{E} & \partial \dot{\mathrm{E}}(*) / \partial \mathrm{P} \\ \partial \dot{\mathrm{P}}(*) / \partial \mathrm{E} & \partial \dot{\mathrm{P}}(*) / \partial \mathrm{P}\end{array}\right]=\left[\begin{array}{cc}-\frac{\mathrm{g}_{\mathrm{e}} \mathrm{E}^{*}}{\mathrm{E}_{\max }} & -\beta \mathrm{E}^{*} \\ \alpha \mathrm{g}_{\mathrm{p}} & -\mathrm{g}_{\mathrm{p}}\end{array}\right]$

The characteristic roots of this Jacobian are

$\lambda_{1,2}=\frac{1}{2}\left\{-\left[\mathrm{g}_{\mathrm{p}}+\frac{\mathrm{g}_{\mathrm{e}} \mathrm{E}^{*}}{\mathrm{E}_{\max }}\right] \pm \sqrt{\left[\mathrm{g}_{\mathrm{p}}+\frac{\mathrm{g}_{\mathrm{e}} \mathrm{E}^{*}}{\mathrm{E}_{\max }}\right]^{2}-4 \mathrm{~g}_{\mathrm{p}} \mathrm{E}^{*}\left[\frac{\mathrm{g}_{\mathrm{e}}}{\mathrm{E}_{\max }}+\alpha \beta\right]}\right.$.

The real part of both eigenvalues is negative because the trace of $\mathrm{J}$ is negative and the discriminant is smaller than the trace squared. The discriminant can be either sign, so the roots can be either two negative real roots or a complex conjugate pair with a negative real part. Therefore, the population and the environment converge either directly or in an inward spiral to the steady state.

\subsection{Global convergence}

We can also show global properties with a phase-plane diagram, Figure 2. Since $\partial \dot{\mathrm{E}} / \partial \mathrm{P}=-\beta \mathrm{E}<0$, the vertical arrows in the phases above (below) the isocline $\dot{\mathrm{E}}=0$ point downward (upward). As $\partial \dot{\mathrm{P}} / \partial \mathrm{E}=\mathrm{g}_{\mathrm{p}}\left\{\mathrm{P} /\left[\alpha\left(\mathrm{E}-\mathrm{E}_{\text {ext }}\right)\right]\right\}^{2}>0$, the horizontal arrows point rightward (leftward) in the phases above (below) the isocline $\dot{\mathrm{P}}=0$. The phase-plane diagram shows the global properties of the environment-population system.

${ }^{2} \dot{\mathrm{E}}_{\mathrm{E}}=\mathrm{g}_{\mathrm{e}}-2 \mathrm{~g}_{\mathrm{e}} \mathrm{E}^{*} / \mathrm{E}_{\max }-\beta \mathrm{P}^{*}$. Note that $\dot{\mathrm{E}}=0$ implies $\beta \mathrm{P}^{*}=\mathrm{g}_{\mathrm{e}}\left[1-\mathrm{E}^{*} / \mathrm{E}_{\max }\right]$, which by substitution into $\dot{\mathrm{E}}_{\mathrm{E}}$ in turn implies $\dot{\mathrm{E}}_{\mathrm{E}}=\mathrm{g}_{\mathrm{e}}-2 \mathrm{~g}_{\mathrm{e}} \mathrm{E}^{*} / \mathrm{E}_{\max }-\mathrm{g}_{\mathrm{e}}+\mathrm{g}_{\mathrm{e}} \mathrm{E}^{*} / \mathrm{E}_{\max }=-\mathrm{g}_{\mathrm{e}} \mathrm{E}^{*} / \mathrm{E}_{\max }$. Recalling that $\mathrm{E}^{*}=\mathrm{E}_{\text {ext }}+(1 / \alpha) \mathrm{P}^{*}, \quad \partial \dot{\mathrm{P}} / \partial \mathrm{E}=\alpha \mathrm{g}_{\mathrm{p}} \mathrm{P}^{* 2} /\left[\alpha\left(\mathrm{E}^{*}-\mathrm{E}_{\text {ext }}\right)\right]^{2}=\alpha \mathrm{g}_{\mathrm{p}} \quad$ and $\partial \dot{\mathrm{P}} / \partial \mathrm{P}=\mathrm{g}_{\mathrm{p}}-2 \mathrm{~g}_{\mathrm{p}} \mathrm{P}^{*} /\left[\alpha\left(\mathrm{E}^{*}-\mathrm{E}_{\mathrm{ext}}\right)\right]=-\mathrm{g}_{\mathrm{p}}$. 
From the diagram we see that $\mathrm{E}$ potentially reaches $\mathrm{E}_{\mathrm{ext}}$ only in quadrant II. Using the line of argument made in the previous section, any path close to $\mathrm{E}_{\mathrm{ext}}$ exits the $\varepsilon$-sized square to the left without hitting the bottom. This rules out extinction.

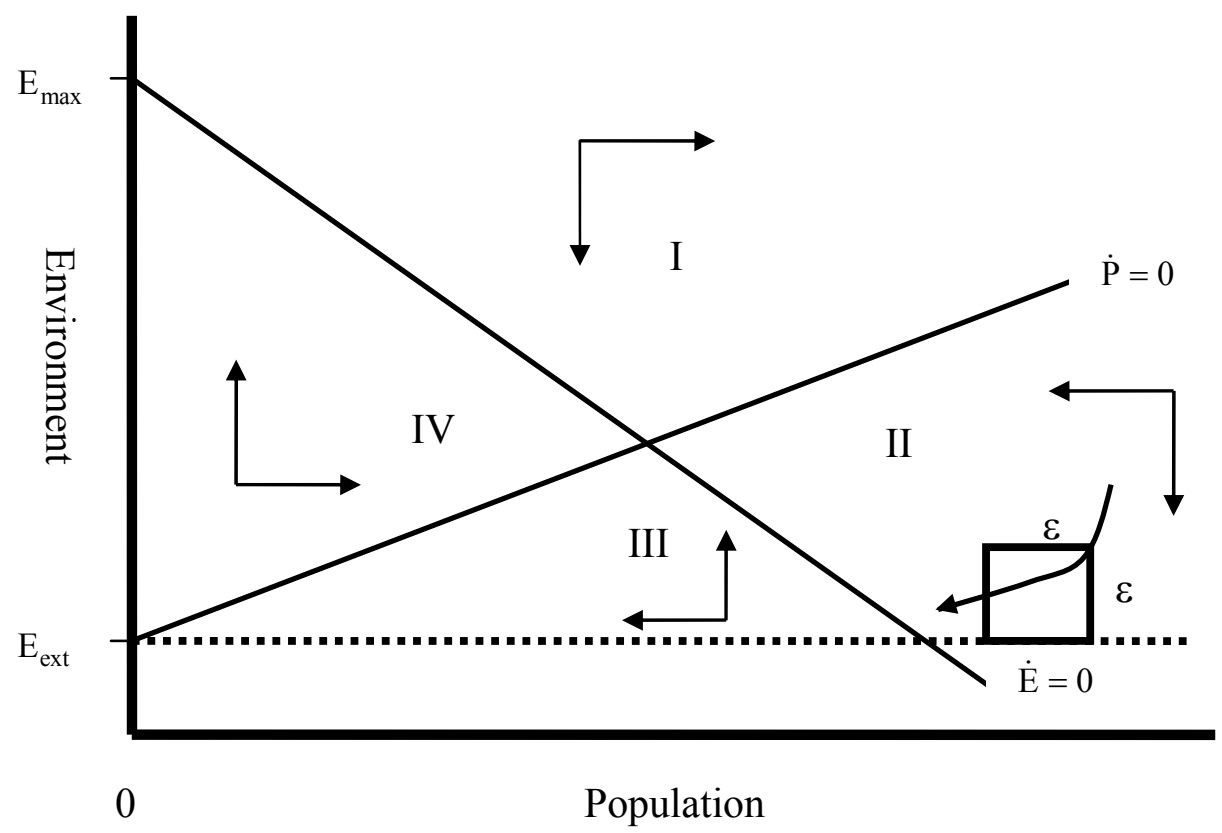

Figure 2. Phase-plane diagram with no extinction

Looking again at Figure 2, the direction of the path in every phase has one arrow that points inwards toward the equilibrium and another that points away. For instance, in phase $\mathrm{I}$, the $\mathrm{E}$ is above $\mathrm{E}^{*}$ but is moving downwards, while $\mathrm{P}$ will be carried beyond $\mathrm{P}^{*}$ in that phase. We bound the true path by a rectangular path that omits the convergent direction. So in phase I, we consider a path that only increases $\mathrm{P}$; in phase II it only decreases E, and so on. The true path is closer to the equilibrium than this rectangular path. The bounding path is a cobweb in the sense of the Cobweb Theorem of Ezekiel (1938). From the Cobweb Theorem we know when the slope of supply exceeds that of demand in absolute value, oscillations are damped. In Figure 2, $\dot{\mathrm{P}}=0$ plays the role of supply and $\dot{\mathrm{E}}=0$ plays the role of demand. Hence, the bounding path converges whenever the slope of $\dot{\mathrm{P}}=0$ is greater in absolute value than that of $\dot{\mathrm{E}}=0$. Since the true path is more inclined toward the steady state than the bounding path, the true path also converges. This property also prevails in the case where the slopes are equal. In this case, the true path must be closer to the equilibrium at each corner of the cobweb. For instance, in quadrant I the bounding path is straight across, whereas the true path is across and down. So the true path moves toward the center at each 
corner of the cobweb and must also converge. Comparing the slopes of $\dot{\mathrm{P}}=0$ and $\dot{\mathrm{E}}$ $=0$ we find that the sufficient, but not necessary, condition for global convergence is

$\beta \mathrm{E}_{\max } \leq \mathrm{g}_{\mathrm{e}} \alpha$.

Namely, if the maximal individual footprint $\left(\beta \mathrm{E}_{\max }\right)$ does not exceed the maximal marginal growth of the carrying capacity $\left(\mathrm{g}_{\mathrm{e}} \alpha\right)$, the joint course of the population and the environment with $\gamma=0=\delta$ converges to the steady state from any initial point ( $\left.\mathrm{P}_{0}>0, \mathrm{E}_{0}>\mathrm{E}_{\mathrm{ext}}\right)$ as long as the public trusts announced changes in the environment. Figure 3 shows a convergent case.

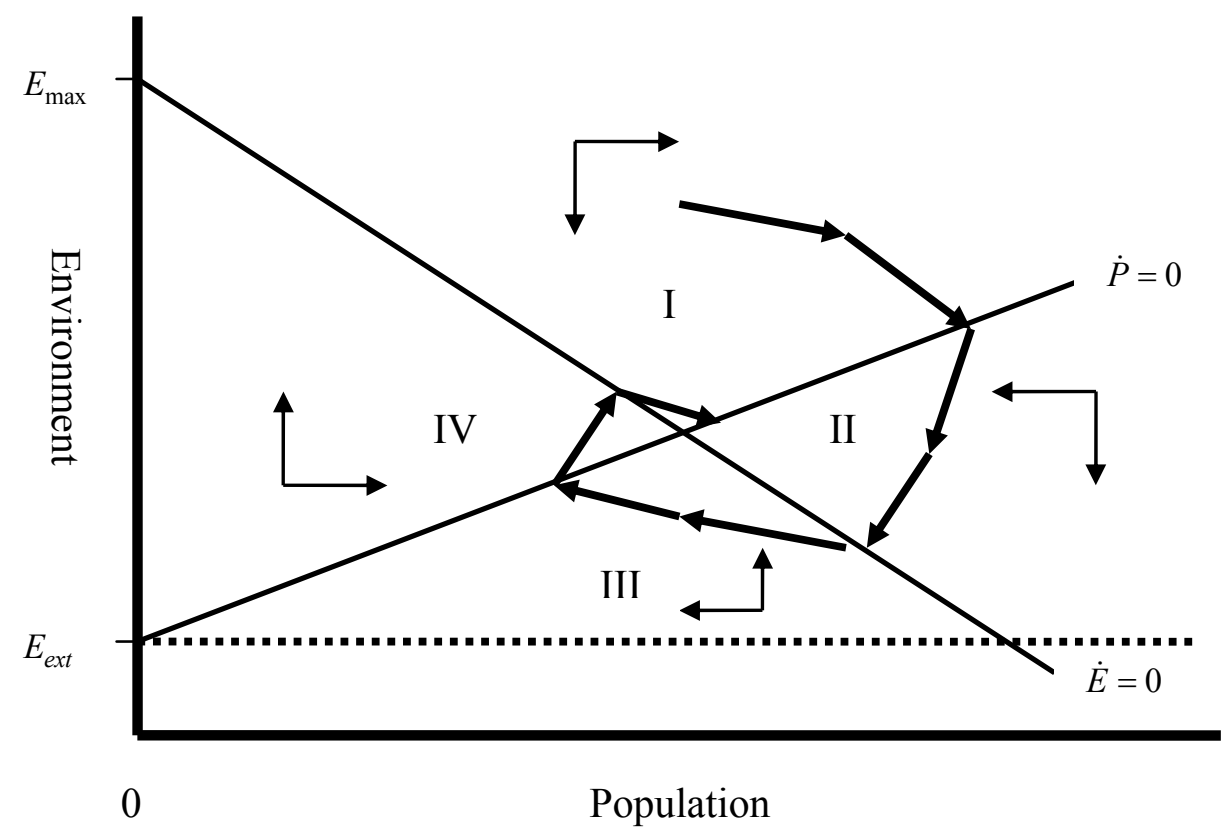

Figure 3. Phase-plane diagram with convergence

\section{Do estimations of the model's parameters suggest skepticism?}

We note that by rearranging terms and taking into account the discrete nature of annual observations, Eq. (3) suggests that the rate of change in the state of the environment is:

$\frac{\mathrm{E}_{\mathrm{t}}-\mathrm{E}_{\mathrm{t}-1}}{\mathrm{E}_{\mathrm{t}-1}}=\mathrm{g}_{\mathrm{e}}-\left(\frac{\mathrm{g}_{\mathrm{e}}}{\mathrm{E}_{\max }}\right) \mathrm{E}_{\mathrm{t}-1}-\beta\left(\frac{1}{1+\delta \mathrm{t}}\right) \frac{\hat{\mathrm{E}}_{\mathrm{t}-1}}{\mathrm{E}_{\mathrm{t}-1}} \mathrm{P}_{\mathrm{t}-1}$

where the subscript $t$ indicates end of year values of the model's variables. We consider the discrete-time equivalent of Eq. (5):

$\hat{\mathrm{E}}_{\mathrm{t}}=\hat{\mathrm{E}}_{0}+\psi\left[\mathrm{E}_{\mathrm{t}}-\mathrm{E}_{0}\right]$ 
and assume that there exists $\mathrm{t}=0$ for which $\hat{\mathrm{E}}_{0}=\mathrm{E}_{0}$. In which case, $\hat{\mathrm{E}}_{\mathrm{t}}=\psi \mathrm{E}_{\mathrm{t}}+(1-\psi) \mathrm{E}_{0}$.

In particular we assume that such an accurate initial observation existed on the eve of the industrial revolution, prior to the accelerated environmental deterioration and population growth that accompanied the process of industrialization. For this reason, and also due to data availability, we start our time-series in 1744 and set $\mathrm{E}_{0}$ to be equal to the state of the environment in that year. Our index of the state of the environment uses the state of the environment in 1744 as a yardstick (numéraire). With $\mathrm{E}_{0}=\mathrm{E}_{1774} \equiv 1, \hat{\mathrm{E}}_{\mathrm{t}-1}=1-\psi\left(1-\mathrm{E}_{\mathrm{t}-1}\right)$ and Eq. (23) is rendered as

$$
\left.\frac{\mathrm{E}_{\mathrm{t}}-\mathrm{E}_{\mathrm{t}-1}}{\mathrm{E}_{\mathrm{t}-1}}=\mathrm{g}_{\mathrm{e}}-\left(\frac{\mathrm{g}_{\mathrm{e}}}{\mathrm{E}_{\max }}\right) \mathrm{E}_{\mathrm{t}-1}+\beta\left(\frac{1}{1+\delta \mathrm{t}}\right)\left[\psi\left(1-\mathrm{E}_{\mathrm{t}-1}\right)-1\right)\right] \frac{\mathrm{P}_{\mathrm{t}-1}}{\mathrm{E}_{\mathrm{t}-1}} .
$$

Due to the prominence of the risks of ocean warming and the associated climate-change for human survival and due to data availability, our construction of the index of the state of the global environment is based on the principal greenhouse gas stock. Approximately eighty percent of the total warming potential of the major greenhouse gases is due to carbon dioxide. In addition, carbon-dioxide accumulation reflects the imbalance between the processes of carbon-dioxide emitting humans, animals and bacteria and the metabolism of carbon-dioxide inhaling plants, as well as the reduced absorptive capacity of the subsequently warmer oceans. Thus, the background concentration of carbon dioxide in the atmosphere can be viewed as a general indicator of the state of the environment. Until very recently in the most developed economies, carbon-dioxide concentration was also a good indicator of more conventional pollution, as combustion is the major source of NOx, SOx, and particulate matter. It is also very well correlated with habitat destruction from mining, timbering, and even farming.

The average annual mole fraction of carbon dioxide in one million molecules of dried air since 1960 is obtained from the records of the United States' National Oceanic and Atmospheric Administration (NOAA) at 3,400 meters above sea level on Mount Mauna Loa, Hawaii. Earlier (1744-1950) atmospheric background carbondioxide concentration (CDC) are obtained from the Siple Station Antarctic ice core (Neftel et al., 1994). We consider $C D C_{1744}$ as a benchmark and use $\left[C D C_{t} / C D C_{1744}\right]^{-1}$ as an indicator of $E_{t}$ for every year between 1744 and 2006, 
inclusive. A time-series data on the world's population (in billions) for the same period is extracted from the World Development Indicators (WDI, The World Bank Group, 2007) for 1951-2009 and from the Historical Estimates of World Population (U.S. Census Bureau, International Programs) for 1744-1950. As the historic figures of human population and background atmospheric concentration of carbon dioxide are not synchronized, it is impossible to expand the database to years earlier than 1960 without extrapolations. Gaps between any two separated historical estimates of CDC and population, denoted by 0 and $J$ (the length of the gap in years), were filled with extrapolations using a computed exponential growth rate (i.e., $\left.(1 / \mathrm{J}) \ln \left(\mathrm{x}_{\mathrm{J}} / \mathrm{x}_{0}\right)\right)$.

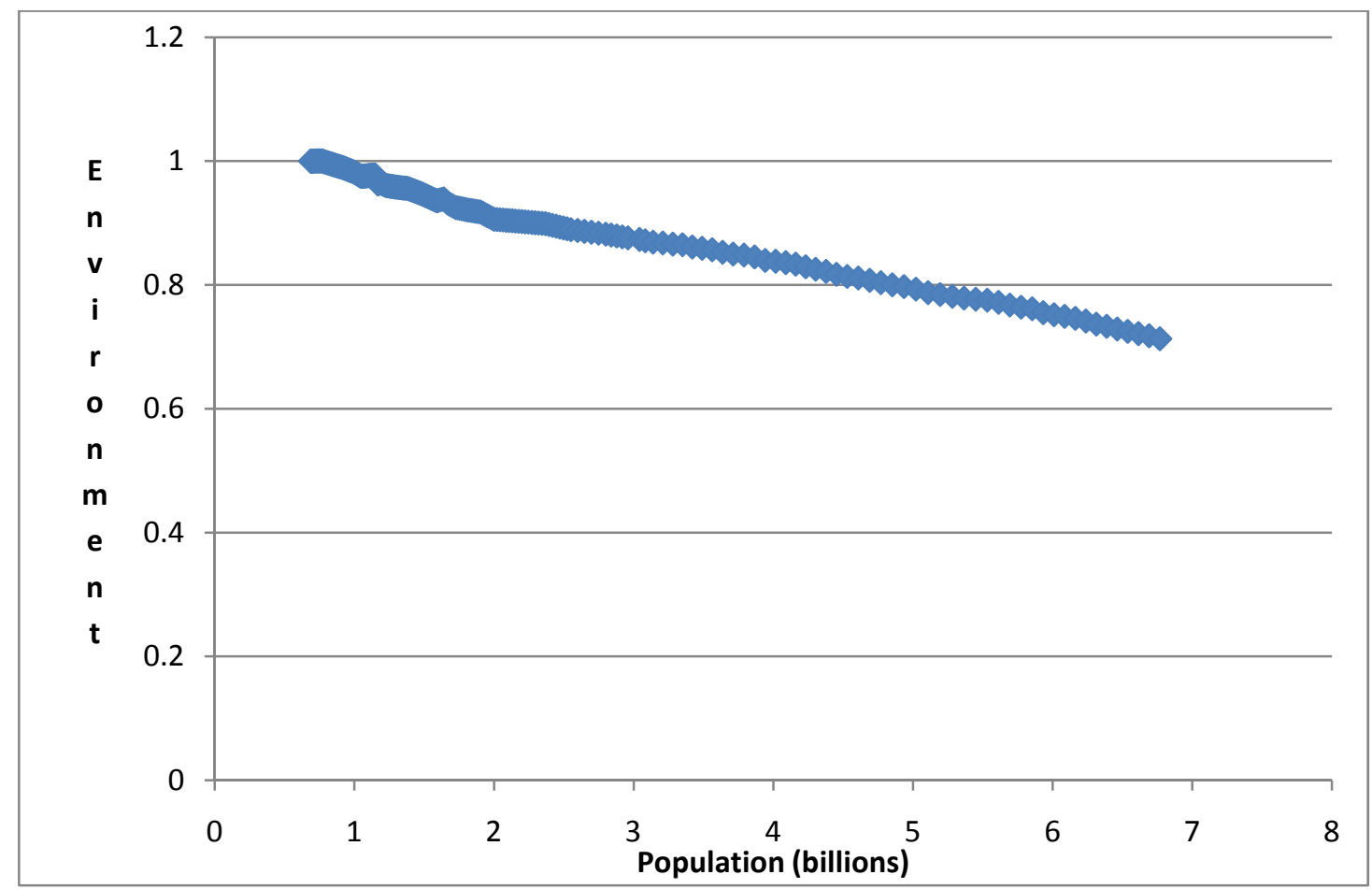

Figure 4. Population and the environment, 1774-2006

In view of the magnitudes of the rates of changes of the environment and population relative to the size of the population, the population figures are taken in billions (with nine digits after the decimal point) in the regression analyses so as to facilitate a non-zero reporting of the estimated value of $\beta$. Thus, the reported estimate of $\beta$ should be interpreted as the footprint of a billion people under progress neutrality $(\delta=0)$ on the state of the environment where the latter is measured on a scale of 0 to 1.

We estimated Eq. (27) using a nonlinear least squares routine and found that the estimates using this technique varied considerably with the choice of initial values. In these estimations, we did find one empirical regularity, the value of $\delta$, was always minute (about 0.0002) and insignificantly different from zero. The estimate of $\psi$, 
though unstable, was generally not significantly different from one. Therefore we set $\delta$ equal to zero and estimated the equation using a grid search on $\psi$. Since the equation is linear otherwise, this method is not subject to numerical problems. We restricted our grid search to $0 \leq \psi \leq 1$.

Table 1 reports the least squares estimates of $g_{e}, g_{e} / E_{\max }$ and $\beta$ obtained with Newey-West $(1987,1994)$ heteroskedasticity and autocorrelation consistent (HAC) adjustment and by using the entire database 1774-2009. Likelihood is maximized at $1-\psi=0$. The other coefficients are all statistically significantly different from zero. Using the likelihood ratio test, $1-\psi$ is different from 1 at the $95 \%$ level, so the best estimate is no skepticism and one can reject complete skepticism. Table 2 reports the estimation results obtained by applying the same method only to the more reliable part of the database: the population estimates and NOAA atmospheric carbondioxide concentration figures for the recent period of years, 1960-2009. The maximum likelihood estimate for skepticism is $1-\psi=0.27$. It is not significantly different from zero using a likelihood ratio test and it is significantly different from full skepticism, 1 only at the $90 \%$ level..

Table 1. Linear Least-squares estimates with predetermined degrees of skepticism, 1774-2009*

\begin{tabular}{|c|c|c|c|c|c|c|}
\hline $\begin{array}{c}\text { Degree of } \\
\text { Skepticism } \\
(1-\psi)\end{array}$ & $\mathrm{g}_{\mathrm{e}}$ & $\frac{\mathrm{g}_{\mathrm{e}}}{\mathrm{E}_{\max }}$ & $\beta$ & $\begin{array}{c}\text { Log } \\
\text { likelihood }\end{array}$ & $\begin{array}{c}\mathrm{R}^{2} \\
\text { adjusted }\end{array}$ & $\begin{array}{c}\mathrm{F}- \\
\text { statistic }\end{array}$ \\
\hline 1 & $\begin{array}{c}0.0025 \\
(0.487)\end{array}$ & $\begin{array}{c}0.0021 \\
(0.418)\end{array}$ & $\begin{array}{c}0.00078 \\
(4.385)\end{array}$ & 1489.9 & 0.728 & 355.2 \\
\hline 0.9 & $\begin{array}{c}0.0033 \\
(0.636)\end{array}$ & $\begin{array}{c}0.0029 \\
(0.564)\end{array}$ & $\begin{array}{c}0.00083 \\
(4.452)\end{array}$ & 1490.3 & 0.729 & 356.6 \\
\hline 0.8 & $\begin{array}{c}0.0042 \\
(0.794)\end{array}$ & $\begin{array}{c}0.0038 \\
(0.720)\end{array}$ & $\begin{array}{c}0.00088 \\
(4.521)\end{array}$ & 1490.8 & 0.730 & 358.2 \\
\hline 0.7 & $\begin{array}{l}0.0052 \\
(0.962)\end{array}$ & $\begin{array}{c}0.0047 \\
(0.886)\end{array}$ & $\begin{array}{c}0.00094 \\
(4.591)\end{array}$ & 1491.2 & 0.731 & 359.9 \\
\hline 0.6 & $\begin{array}{l}0.0033 \\
(0.630)\end{array}$ & $\begin{array}{c}0.0029 \\
(0.558)\end{array}$ & $\begin{array}{c}0.00083 \\
(4.441)\end{array}$ & 1490.3 & 0.729 & 356.4 \\
\hline 0.5 & $\begin{array}{l}0.0074 \\
(1.280)\end{array}$ & $\begin{array}{l}0.0068 \\
(1.200)\end{array}$ & $\begin{array}{c}0.0011 \\
(4.666)\end{array}$ & 1491.9 & 0.732 & 362.5 \\
\hline 0.4 & $\begin{array}{l}0.0087 \\
(1.459)\end{array}$ & $\begin{array}{c}0.0081 \\
(1.378)\end{array}$ & $\begin{array}{c}0.0012 \\
(4.713)\end{array}$ & 1492.4 & 0.734 & 364.3 \\
\hline 0.3 & $\begin{array}{l}0.0102 \\
(1.641)\end{array}$ & $\begin{array}{c}0.0095 \\
(1.559)\end{array}$ & $\begin{array}{c}0.0013 \\
(4.750)\end{array}$ & 1493.0 & 0.735 & 366.4 \\
\hline 0.2 & $\begin{array}{l}0.0123 \\
(1.909)\end{array}$ & $\begin{array}{c}0.0115 \\
(1.826)\end{array}$ & $\begin{array}{c}0.0014 \\
(4.903)\end{array}$ & 1494.4 & 0.737 & 371.6 \\
\hline 0.1 & 0.0138 & $\begin{array}{c}0.0129 \\
(1.995)\end{array}$ & $\begin{array}{c}0.0015 \\
(1.913)\end{array}$ & 1494.2 & 0.737 & 370.9 \\
\hline 0 & $\begin{array}{l}0.0158 \\
(2.158)\end{array}$ & $\begin{array}{c}0.0149 \\
(2.077)\end{array}$ & $\begin{array}{c}0.0017 \\
(4.776)\end{array}$ & 1494.8 & 0.738 & 373.3 \\
\hline
\end{tabular}

*t-values in parentheses. 
Table 2. Linear Least-squares estimates with predetermined degrees of skepticism, 1960-2009*

\begin{tabular}{|c|c|c|c|c|c|c|}
\hline $\begin{array}{c}\text { Degree of } \\
\text { Skepticism } \\
(1-\psi)\end{array}$ & $\mathrm{g}_{\mathrm{e}}$ & $\frac{g_{e}}{E_{\max }}$ & $\beta$ & $\begin{array}{c}\text { Log } \\
\text { likelihood }\end{array}$ & $\begin{array}{c}\mathrm{R}^{2} \\
\text { adjusted }\end{array}$ & $\begin{array}{c}\text { F- } \\
\text { statistic }\end{array}$ \\
\hline 1 & $\begin{array}{l}0.0811 \\
(0.797)\end{array}$ & $\begin{array}{l}0.0742 \\
(0.808)\end{array}$ & $\begin{array}{l}0.0032 \\
(0.990)\end{array}$ & 255.898 & 0.287 & 10.673 \\
\hline 0.9 & $\begin{array}{l}0.1046 \\
(0.970)\end{array}$ & $\begin{array}{c}0.095 \\
(0.980)\end{array}$ & $\begin{array}{l}0.0040 \\
(1.152)\end{array}$ & 256.093 & 0.293 & 10.943 \\
\hline 0.8 & $\begin{array}{l}0.1319 \\
(1.168) \\
\end{array}$ & $\begin{array}{l}0.1193 \\
(1.177) \\
\end{array}$ & $\begin{array}{l}0.0051 \\
(1.341) \\
\end{array}$ & 256.344 & 0.300 & 11.293 \\
\hline 0.7 & $\begin{array}{l}0.1616 \\
(1.377)\end{array}$ & $\begin{array}{l}0.1454 \\
(1.385) \\
\end{array}$ & $\begin{array}{l}0.0062 \\
(1.543) \\
\end{array}$ & 256.651 & 0.309 & 11.725 \\
\hline 0.6 & $\begin{array}{l}0.1900 \\
(1.566) \\
\end{array}$ & $\begin{array}{l}0.1701 \\
(1.573)\end{array}$ & $\begin{array}{l}0.0074 \\
(1.725) \\
\end{array}$ & 256.993 & 0.318 & 12.213 \\
\hline 0.5 & $\begin{array}{l}0.2114 \\
(1.803) \\
\end{array}$ & $\begin{array}{l}0.1884 \\
(1.809) \\
\end{array}$ & $\begin{array}{l}0.0084 \\
(1.967) \\
\end{array}$ & 257.323 & 0.327 & 12.690 \\
\hline 0.4 & $\begin{array}{l}0.2204 \\
(2.091) \\
\end{array}$ & $\begin{array}{l}0.1954 \\
(2.097)\end{array}$ & $\begin{array}{l}0.0090 \\
(2.272)\end{array}$ & 257.574 & 0.334 & 13.057 \\
\hline 0.3 & $\begin{array}{l}0.2146 \\
(2.369) \\
\end{array}$ & $\begin{array}{l}0.1894 \\
(2.375)\end{array}$ & $\begin{array}{l}0.0090 \\
(2.579) \\
\end{array}$ & 257.695 & 0.365 & 13.236 \\
\hline 0.27 & $\begin{array}{l}0.2102 \\
(2.401)\end{array}$ & $\begin{array}{l}0.1853 \\
(2.406)\end{array}$ & $\begin{array}{l}0.0089 \\
(2.618) \\
\end{array}$ & 257.703 & 0.338 & 13.249 \\
\hline 0.2 & $\begin{array}{l}0.1966 \\
(2.437) \\
\end{array}$ & $\begin{array}{l}0.1726 \\
(2.441) \\
\end{array}$ & $\begin{array}{l}0.0086 \\
(2.672) \\
\end{array}$ & 257.679 & 0.337 & 13.213 \\
\hline 0.1 & $\begin{array}{l}0.1717 \\
(2.311) \\
\end{array}$ & $\begin{array}{l}0.1500 \\
(2.314) \\
\end{array}$ & $\begin{array}{l}0.0078 \\
(2.568)\end{array}$ & 257.561 & 0.334 & 13.038 \\
\hline 0 & $\begin{array}{l}0.1451 \\
(2.100) \\
\end{array}$ & $\begin{array}{l}0.1260 \\
(2.101) \\
\end{array}$ & $\begin{array}{l}0.0070 \\
(2.377) \\
\end{array}$ & 257.388 & 0.329 & 12.785 \\
\hline
\end{tabular}

*t-values in parentheses.

\section{A few words on the rational population size and use of the environment}

For the reasons indicated in the introduction, our L-V environment-population model included an ad hoc feedback. As economists we are interested in describing a rational growth and use of natural resources. For this purpose, we modify the model by considering a perpetual rational representative human being who takes the state of the environment and population-size to be endogenous, interrelated stocks, and who, in addition to consumption (c), enjoys the environmental amenities and social opportunities stemming from those stocks. His lifetime utility is, for tractability, additively separable and his instantaneous utility is depicted by $\mathrm{u}(\mathrm{E}(\mathrm{t}), \mathrm{P}(\mathrm{t}), \mathrm{c}(\mathrm{t}))$. His marginal instantaneous utilities from consumption and the state of the environment are positive but diminishing $\left(\mathrm{u}_{\mathrm{c}}>0, \mathrm{u}_{\mathrm{cc}}<0, \mathrm{u}_{\mathrm{E}}>0, \mathrm{u}_{\mathrm{EE}}<0\right)$ and living in a good environment complements his enjoyment of consumption $\left(\mathrm{u}_{\mathrm{cE}}>0\right)$. Inherently social, he prefers company to solitary $\left(\mathrm{u}_{\mathrm{P}}(\mathrm{E}, 0, \mathrm{c})>0\right.$ and $\left.\mathrm{u}_{\mathrm{cP}}(\mathrm{E}, 0, \mathrm{c})>0\right)$. Due to diminishing bonds and evolving conflicts, his marginal enjoyment of company 
decreases and can become negative as the population grows $\left(\mathrm{u}_{\mathrm{PP}}<0\right)$. Also his enjoyment of the environment diminishes as the world becomes congested $\left(\mathrm{u}_{\mathrm{EP}}<0\right)$.

In a perfectly rational setting there is no room for non-objective noise and hence there is no skepticism about announced objectively measured changes in the state of the environment. In such a setting, $\hat{E}(t)=E(t)$. Ideally, time-preferences are weak. They are represented by a small fixed rate, $\rho \geq 0$. A consumption-path that maximizes the representative human's lifetime utility $\int_{0}^{\infty} \mathrm{e}^{-\rho \mathrm{t}} \mathrm{u}(\mathrm{E}(\mathrm{t}), \mathrm{P}(\mathrm{t}), \mathrm{c}(\mathrm{t})) \mathrm{dt}$ subject to the motion equations of the environment and population can be viewed as rational.

To facilitate a description of the representative human's rationally possible long-term situation (steady state) we assume that his consumption is equal to his production, his production input is the environment, and his technology is timeinvariant. This assumption is represented by a time-invariant relationship between the representative human's exploitation of the environment and consumption, which, for tractability, displays a constant marginal exploitation, $\mu>0$ (exploitationconsumption ratio), and renders the representative human's instantaneous footprint equal to $\mu \mathrm{c}(\mathrm{t})$. Thus, the motion equation (3) is replaced by $\dot{\mathrm{E}}(\mathrm{t})=\mathrm{g}_{\mathrm{e}} \mathrm{E}(\mathrm{t})\left[1-\mathrm{E}(\mathrm{t}) / \mathrm{E}_{\max }\right]-\mu \mathrm{c}(\mathrm{t}) \mathrm{P}(\mathrm{t})$. Time-invariant technology is also represented by a fixed relationship between the carrying capacity and the state of the environment. Hence, the motion equation (7) is replaced by $\dot{\mathrm{P}}(\mathrm{t})=\mathrm{g}_{\mathrm{p}} \mathrm{P}(\mathrm{t})\left\{1-\mathrm{P}(\mathrm{t}) /\left[\alpha\left(\mathrm{E}(\mathrm{t})-\mathrm{E}_{\text {ext }}\right)\right]\right\}$.

The present-value Hamiltonian associated with the representative human's optimal control problem is

$$
\mathrm{H}=\mathrm{e}^{-\rho \mathrm{t}} \mathrm{u}(\mathrm{E}, \mathrm{P}, \mathrm{c})+\lambda\left[\mathrm{g}_{\mathrm{e}} \mathrm{E}\left(1-\mathrm{E} / \mathrm{E}_{\max }\right)-\mu \mathrm{cP}\right]+\phi\left[\mathrm{g}_{\mathrm{p}} \mathrm{P}\left(1-\mathrm{P} /\left(\alpha\left(\mathrm{E}-\mathrm{E}_{\text {ext }}\right)\right)\right]\right.
$$

where the time index is omitted for compactness. The co-state variables $\lambda$ and $\phi$ represent the shadow values of the environment and population, respectively, for the representative human. While $\lambda$ is always positive [as implied by the optimality condition (30)], $\phi$ can be non-positive when the population is sufficiently large for the adverse effect of a heavily foot-printed and congested environment to dominate the weakened positive effect of opportunities for socializing and marketing 
(agglomeration) on personal utility. For this reason, $\mathrm{H}$ might not be concave in the state variables $\mathrm{E}$ and $\mathrm{P}$ when the population is large. Although $\mathrm{H}$ is concave in the control variable c, the Mangasarian theorem on the sufficiency of Pontryagin's maximum-principle conditions is not necessarily applicable as the shadow value of population can be negative. Hence, the aforesaid motion equations of $\mathrm{E}$ and $\mathrm{P}$ and the following additional necessary conditions for maximum lifetime utility are not claimed to be sufficient:

$$
\begin{aligned}
& \dot{\lambda}=-\mathrm{e}^{-\rho \mathrm{t}} \mathrm{u}_{\mathrm{E}}(\mathrm{E}, \mathrm{P}, \mathrm{c})-\lambda \mathrm{g}_{\mathrm{e}}\left[1-2 \mathrm{E} / \mathrm{E}_{\max }\right]-\phi \mathrm{g}_{\mathrm{p}} \mathrm{P}^{2} /\left[\alpha\left(\mathrm{E}-\mathrm{E}_{\mathrm{ext}}\right)^{2}\right] \\
& \left\{\mathrm{e}^{-\rho \mathrm{t}} \mathrm{u}_{\mathrm{c}}(\mathrm{E}, \mathrm{P}, \mathrm{c})-\lambda \mu \mathrm{P}=0\right\} \Rightarrow\left\{\lambda=\mathrm{e}^{-\rho \mathrm{t}} \mathrm{u}_{\mathrm{c}}(\mathrm{E}, \mathrm{P}, \mathrm{c}) /(\mu \mathrm{P})\right\} \\
& \dot{\phi}=-\mathrm{e}^{-\rho \mathrm{t}} \mathrm{u}_{\mathrm{P}}(\mathrm{E}, \mathrm{P}, \mathrm{c})+\lambda \mu \mathrm{c}-\phi \mathrm{g}_{\mathrm{p}}\left[1-2 \mathrm{P} /\left(\alpha\left(\mathrm{E}-\mathrm{E}_{\mathrm{ext}}\right)\right)\right] \\
& \lim _{\mathrm{t} \rightarrow \infty} \lambda(\mathrm{t}) \mathrm{E}(\mathrm{t})=0 \\
& \lim _{\mathrm{t} \rightarrow \infty} \phi(\mathrm{t}) \mathrm{P}(\mathrm{t})=0
\end{aligned}
$$

The optimality condition (30) requires equality between the shadow value of the environment and ratio of the marginal utility from consumption to the marginal environmental degradation caused by consumption. In addition, the adjoint equation (29) reveals that the rational rate of change of the shadow value of the environment decreases with the marginal regeneration of the environment and people's marginal rate of substitution between consumption and environmental amenities and increases with the marginal growth of population when the population is sufficiently large for its shadow value being negative $(\phi<0)$. The effects of the latter two factors are amplified by the exploitation-consumption ratio $\mu$ :

$$
\begin{aligned}
\dot{\lambda} / \lambda= & -\mathrm{g}_{\mathrm{e}}\left[1-2 \mathrm{E} / \mathrm{E}_{\max }\right] \\
& -\mu \mathrm{P}\left[\mathrm{u}_{\mathrm{E}}(\mathrm{E}, \mathrm{P}, \mathrm{c}) / \mathrm{u}_{\mathrm{c}}(\mathrm{E}, \mathrm{P}, \mathrm{c})\right]-\phi \mu \mathrm{Pg}_{\mathrm{p}} \mathrm{P}^{2} /\left[\alpha\left(\mathrm{E}-\mathrm{E}_{\mathrm{ext}}\right)^{2} \mathrm{e}^{-\rho \mathrm{t}} \mathrm{u}_{\mathrm{c}}(\mathrm{E}, \mathrm{P}, \mathrm{c})\right]
\end{aligned}
$$

The necessary conditions (29) and (30) further imply that in steady state $\left(\mathrm{P}^{*}, \mathrm{E}^{*}, \mathrm{c}^{*}\right)$

$$
\begin{aligned}
\phi \mathrm{g}_{\mathrm{p}}= & -\mathrm{e}^{-\rho \mathrm{t}} \mathrm{u}_{\mathrm{E}}\left(\mathrm{E}^{*}, \mathrm{P}^{*}, \mathrm{c}^{*}\right)\left[\alpha\left(\mathrm{E}^{*}-\mathrm{E}_{\mathrm{ext}}\right)^{2}\right] / \mathrm{P}^{* 2} \\
& -\mathrm{e}^{-\rho \mathrm{t}}\left[\mathrm{u}_{\mathrm{c}}\left(\mathrm{E}^{*}, \mathrm{P}^{*}, \mathrm{c}^{*}\right) /\left(\mu \mathrm{P}^{*}\right)\right] \mathrm{g}_{\mathrm{e}}\left[1-2 \mathrm{E}^{*} / \mathrm{E}_{\max }\right]\left[\alpha\left(\mathrm{E}^{*}-\mathrm{E}_{\mathrm{ext}}\right)^{2}\right] / \mathrm{P}^{* 2}
\end{aligned}
$$

Recalling (31) and (30), in steady state also

$$
\begin{aligned}
\phi \mathrm{g}_{\mathrm{p}}= & -\mathrm{e}^{-\rho \mathrm{t}} \mathrm{u}_{\mathrm{P}}\left(\mathrm{E}^{*}, \mathrm{P}^{*}, \mathrm{c}^{*}\right) /\left[1-2 \mathrm{P}^{*} /\left(\alpha\left(\mathrm{E}^{*}-\mathrm{E}_{\mathrm{ext}}\right)\right)\right] \\
& +\mathrm{e}^{-\rho \mathrm{t}}\left[\mathrm{u}_{\mathrm{c}}\left(\mathrm{E}^{*}, \mathrm{P}^{*}, \mathrm{c}^{*}\right) /(\mu \mathrm{P})\right] \mu \mathrm{c}^{*} /\left[1-2 \mathrm{P} * /\left(\alpha\left(\mathrm{E}^{*}-\mathrm{E}_{\mathrm{ext}}\right)\right)\right] .
\end{aligned}
$$

From (35) and (36), (E*, $\left.\mathrm{P}^{*}, \mathrm{c}^{*}\right)$ should satisfy: 


$$
\begin{aligned}
- & \mathrm{u}_{\mathrm{P}}\left(\mathrm{E}^{*}, \mathrm{P}^{*}, \mathrm{c}^{*}\right) /\left[1-2 \mathrm{P} * /\left(\alpha\left(\mathrm{E}^{*}-\mathrm{E}_{\mathrm{ext}}\right)\right)\right] \\
& +\left[\mathrm{u}_{\mathrm{c}}\left(\mathrm{E}^{*}, \mathrm{P}^{*}, \mathrm{c}^{*}\right) /\left(\mu \mathrm{P}^{*}\right)\right] \mu \mathrm{c} * /\left[1-2 \mathrm{P} * /\left(\alpha\left(\mathrm{E}^{*}-\mathrm{E}_{\mathrm{ext}}\right)\right)\right] \\
= & -\mathrm{u}_{\mathrm{E}}\left(\mathrm{E}^{*}, \mathrm{P}^{*}, \mathrm{c}^{*}\right)\left[\alpha\left(\mathrm{E}^{*}-\mathrm{E}_{\mathrm{ext}}\right)^{2}\right] / \mathrm{P}^{* 2} \\
& -\left[\mathrm{u}_{\mathrm{c}}\left(\mathrm{E}^{*}, \mathrm{P}^{*}, \mathrm{c}^{*}\right) /\left(\mu \mathrm{P}^{*}\right)\right] \mathrm{g}_{\mathrm{e}}\left[1-2 \mathrm{E}^{*} / \mathrm{E}_{\max }\right]\left[\alpha\left(\mathrm{E}^{*}-\mathrm{E}_{\mathrm{ext}}\right)^{2}\right] / \mathrm{P}^{* 2} .
\end{aligned}
$$

Clearly, the steady state is not unique. Recalling the motion equations of the environment and population, any steady-state combination should also satisfy:

$\mu \mathrm{c} * \mathrm{P} *=\mathrm{g}_{\mathrm{e}} \mathrm{E} *\left[1-\mathrm{E} * / \mathrm{E}_{\max }\right]$

and

$$
\mathrm{P}^{*}=\alpha\left(\mathrm{E}^{*}-\mathrm{E}_{\mathrm{ext}}\right) \text {. }
$$

Insight on the steady-state consumption (per capita) can be gained by some manipulations of the equation-system (37), (38) and (39). From Eq. (38) and Eq. (39), the steady-state consumption is

$$
\mathrm{c}^{*}=\frac{\mathrm{g}_{\mathrm{e}} \mathrm{E}^{*}\left[1-\mathrm{E}^{*} / \mathrm{E}_{\max }\right]}{\mu \alpha\left(\mathrm{E}^{*}-\mathrm{E}_{\mathrm{ext}}\right)} .
$$

The substitution of the right-hand side of Eq. (39) into Eq. (37) for P* implies

$$
\mathrm{c}^{*}=\frac{\left[\mathrm{u}_{\mathrm{P}}\left(\mathrm{E}^{*}, \mathrm{P}^{*}, \mathrm{c}^{*}\right)+\mathrm{u}_{\mathrm{E}}\left(\mathrm{E}^{*}, \mathrm{P}^{*}, \mathrm{c}^{*}\right) / \alpha\right] \alpha\left(\mathrm{E}^{*}-\mathrm{E}_{\mathrm{ext}}\right)}{\mathrm{u}_{\mathrm{c}}\left(\mathrm{E}^{*}, \mathrm{P}^{*}, \mathrm{c}^{*}\right)}+\mathrm{g}_{\mathrm{e}}\left[1-2 \mathrm{E} * / \mathrm{E}_{\max }\right] /(\mu \alpha) \text {. }
$$

From Eq. (40),

$$
\mathrm{g}_{\mathrm{e}}\left[1-2 \mathrm{E}^{*} / \mathrm{E}_{\max }\right]=\left[\alpha\left(\mathrm{E}^{*}-\mathrm{E}_{\mathrm{ext}}\right) / \mathrm{E}^{*}\right] \mu \mathrm{c} *-\mathrm{g}_{\mathrm{e}} \mathrm{E} / \mathrm{E}_{\max } \text {. }
$$

The substitution of this equality into Eq. (41) and rearrangement of terms imply

$$
\mathrm{c}^{*}=\frac{\left[\mathrm{u}_{\mathrm{P}}\left(\mathrm{E}^{*}, \mathrm{P}^{*}, \mathrm{c}^{*}\right)+\mathrm{u}_{\mathrm{E}}\left(\mathrm{E}^{*}, \mathrm{P}^{*}, \mathrm{c}^{*}\right) / \alpha\right] \alpha\left(\mathrm{E}^{*}-\mathrm{E}_{\mathrm{ext}}\right) \mathrm{E}^{*}}{\mathrm{u}_{\mathrm{c}}\left(\mathrm{E}^{*}, \mathrm{P}^{*}, \mathrm{c}^{*}\right) \mathrm{E}_{\mathrm{ext}}}-\frac{\mathrm{g}_{\mathrm{e}}}{\mu \alpha \mathrm{E}_{\mathrm{max}} \mathrm{E}_{\mathrm{ext}}} \mathrm{E}^{* 2}
$$

Since $\mathrm{u}_{\mathrm{P}}$ is diminished by population growth and can become negative, the marginal instantaneous utility from the environment $\left(\mathrm{u}_{\mathrm{E}}\right)$ in an interior steady state $\left(\mathrm{c}^{*}>0\right)$ with a large population must be larger than the marginal instantaneous utility from the environment in an interior steady state with a smaller population. This implies that before reaching the irreversible state of annihilation, $E_{\text {ext }}$, humans must have a strongly intensifying marginal instantaneous utility from the environment as it becomes degraded. Moreover, the stronger the preference of human beings for consumption (reflected by a larger $\mathrm{u}_{\mathrm{c}}$ for any level of $\mathrm{c}$ given $\mathrm{P}$ and $\mathrm{E}$ ) is, the stronger the intensification of the marginal instantaneous utility from the environment 
required for converging to an interior steady state and avoiding self-inflicted extinction.

\section{Conclusion}

While the previous section outlined a framework of rational population growth and use of the environment, the earlier, main sections of the paper attempted to derive the joint course of the human population and the environment within a more realistic framework. The rounds of international meetings have revealed the inability of nations to cooperate effectively on curbing environmental degradation. We therefore modeled the environment and population with uncoordinated individual responses to the perceived state of the environment. Our analysis introduced two integrating factors into the laws of motion of the environment-population system's state variables in a Lotka-Volterra type model. The environment's capacity to carry human population was introduced into the population's motion equation. People's concerns for the environment were introduced into the environment's motion equation. We considered these integrating factors to be endogenous. Due to the open-access nature of the environment and a spontaneous reaction of population growth to environmental conditions, we took them to evolve in non-optimal manners.

Earth's carrying capacity declines as the environment deteriorates, and the exposure to a deteriorating environment raises the level of humans' environmental concern. However, people's concern for the environment is weakened by skepticism about news on changes in the state of the environment. Our analysis of the joint dynamics of the state of the environment and human population suggests that in the absence of further progress, or regression, the proposed uncoordinated, ad hoc environment-population system has a unique, interior, stable steady state. Off steady state, the course of the environment and population displays oscillations that do not lead to extinction and can be proven to be damped only in the ideal case of publicly trusted accurately measured changes in the state of the environment. Our estimation results of the parameters of the model suggest that people's degree of skepticism about news on the state of the environment is low and possibly nil. Reducing the nonobjective noise about the state of the environment is essential for preventing skepticism and, consequently, excessive environmental degradation and extinction of the human kind. 


\section{REFERENCES}

Andreoni, James and Levinson, Arik. "The simple analytics of the environmental Kuznets curve." Journal of Public Economics, May 2001, 80(2), pp. 269-286.

Anderies, John M. "Economic development, demographics, and renewable resources: A dynamical systems approach." Environment and Development Economics, 2003, 8, pp. 219-246.

Berck, Peter. "Open Access and Extinction.” Econometrica, 1979, 47(4), pp. 877882.

Berck, Peter and Perloff, Jeffry. "An Open Access Fishery with Rational Expectations." Econometrica, 1984, 52(2), pp. 489-506.

Brander, James A. and Taylor, M. Scott. "The Simple Economics of Easter Island: A Ricardo-Malthus Model of Renewable Resource Use." American Economic Review, March 1998, 88(1), pp. 119-138.

Carson , Richard T. "The Environmental Kuznets Curve: Seeking Empirical Regularity and Theoretical Structure." Review of Environmental Economics and Policy, 2010, 4(1), pp. 3-23.

Chavas, Jean-Paul. "On Impatience, Economic Growth and the Environmental Kuznets Curve: A Dynamic Analysis of Resource Management." Environmental and Resource Economics, June 2004, 28(2), pp. 123-152.

Clark, Colin W. Mathematical Bioeconomics. New York: John Wiley \& Sons, 1976.

Cohen, Joel E. How Many people can the Earth Support? New York: Norton \& Company, 1996.

Diekmann, Andreas and Franzen, Axel. "The Wealth of Nations and Environmental Concern.” Environment and Behavior, 1999, 31(4), pp. 540- 49.

Dunlap, Riley E.; Gallup, George H. and Gallup, M. Alec. "Of Global Concern: Results of the Health of the Planet Survey." Environment , 1993, 35(7- 15), 33-39.

Dunlap, Riley E. and Mertig, G. Angela. "Global Environmental Concern: An Anomaly for Postmaterialism.” Social Science Quarterly, 1997, 78(1), pp. 24-29.

Ezekiel, Mordecai. "The Cobweb Theorem." Quarterly Journal of Economics, February 1938, 52(2), pp. 255-280.

Faria, João R. "What Happened to the Neanderthals? The Survival Trap." Kyklos, 2000, 53, 161-172.

Franzen, Axel. "Environmental Attitudes in International Comparison: An Analysis of the ISSP Surveys 1993 and 2000." Social Science Quarterly, 2003, 84(2), pp. 297308 . 
Grossman, Gene M. and Krueger, B. Alan. "Economic Growth and the Environment." Quarterly Journal of Economics, May 1995, 110(2), pp. 353-377.

Horan, Richard D. and Bulte, H. Erwin. "Optimal and Open Access Harvesting of Multi-Use Species in a Second-Best World." Environmental and Resource Economics, July 2004, 28(3), pp. 251-272.

Inglehart, Ronald. "Public Support for the Environmental Protection: Objective Problems and Subjective Values in 43 Societies." PS: Political Science \& Politics, 1995, 28, pp. 57- 72.

Inglehart, Ronald. Modernization and Postmodernization: Cultural, Economic, and Political Change in 43 Societies. Princeton: Princeton University Press, 1997.

Lotka, A.J. Elements of Physical Biology, Baltimore: Williams and Wilkins, 1925.

Malthus, Thomas R. An Essay on the Principle of Population. In Oxford World's Classic reprint, 1798.

Meadows, Donella H.; Meadows, Dennis L.; Randers, Jørgen and Behrens III, William W. The Limits to Growth. Washington DC: Potomac Associates, 1972.

Meadows, Dennis L.; Behrens III, William W.; Meadows, Donella H.; Naill, Roger F.; Randers, Jørgen and Zahn, Erich K.O.. Dynamics of Growth in a Finite World. Massachusetts: Wright-Allen Press, Inc., 1974.

Mendelsohn, Robert. "Symposium: The Economics of Climate Change: The Stern Review and Its Critics: Is the Stern Review an Economic Analysis?" Review of Environmental Economics and Policy, 2008, 2(1), pp. 45-60.

Neftel, A., H. Friedli, E. Moor, H. Lötscher, H. Oeschger, U. Siegenthaler, and B. Stauffer. 1994. Historical $\mathrm{CO}_{2}$ record from the Siple Station ice core. In Trends: A Compendium of Data on Global Change. Carbon Dioxide Information Analysis Center, Oak Ridge National Laboratory, U.S. Department of Energy, Oak Ridge, Tenn., U.S.A.

Newey, Whitney K. and West, D. Kenneth. "A Simple, Positive-Definite, Heteroskedasticity and Autocorrelation Consistent Covariance Matrix." Econometrica, 1987, 55(3), pp. 703-708.

Newey, Whitney K. and West, D. Kenneth. "Automatic Lag Selection in Covariance Matrix Estimation.” Review of Economic Studies, 1994, 61, pp. 631-653.

Nordhaus, William D. "The 'Dice' Model: Background and Structure of a Dynamic Integrated Climate-Economy Model of the Economics of Global Warming." Cowles Foundation Discussion Paper No. 1009, Yale University, 1992.

Nordhaus, William D. A Question of Balance: Weighing the Options on Global Warming Policies. New Haven: Yale University Press, 2008. 
Ramsey, Frank P. (1928), “A Mathematical Theory of Saving”, Economic Journal, 1928, 38(152), pp. 543-559.

Selden, Thomas M. and Song, Daqing. "Environmental quality and development: Is there a Kuznets curve for air pollution emissions?" Journal of Environmental Economics and Management, 1994, 27(2), pp. 147-162.

Shafik, N. and Bandyopadhyay, S. "Economic growth and environmental quality: Time series and cross-section evidence." World Bank, Policy research working paper WPS904, 1992.

Volterra, V. Leçons sur la Théorie Mathématique de la Lutte pour la Vie, Paris: Gauthier-Villars, 1931. 


\section{Appendix}

\section{Computation of the steady-states indicated by equation (10)}

With a neutral multi-facet process, the steady-state conditions of the system (3), (5) and (7) are:

$$
\begin{aligned}
& \mathrm{g}_{\mathrm{e}} \mathrm{E}\left(1-\frac{\mathrm{E}}{\mathrm{E}_{\max }}\right)-\beta\left[\hat{\mathrm{E}}_{0}+\psi\left(\mathrm{E}-\mathrm{E}_{0}\right)\right] \mathrm{P}=0 \\
& \mathrm{P}_{\mathrm{ss}}=\alpha\left[\mathrm{E}_{\mathrm{ss}}-\mathrm{E}_{\text {ext }}\right]
\end{aligned}
$$

By substitution,

$$
\mathrm{g}_{\mathrm{e}} \mathrm{E}_{\mathrm{ss}}\left(1-\frac{\mathrm{E}_{\mathrm{sS}}}{\mathrm{E}_{\max }}\right)-\beta\left[\hat{\mathrm{E}}_{0}+\psi\left(\mathrm{E}_{\mathrm{ss}}-\mathrm{E}_{0}\right)\right] \alpha\left[\mathrm{E}_{\mathrm{ss}}-\mathrm{E}_{\mathrm{ext}}\right]=0
$$

By rearranging terms,

$$
\begin{array}{r}
{\left[\left(\mathrm{g}_{\mathrm{e}} / \mathrm{E}_{\max }\right)+\alpha \beta \psi\right] \mathrm{E}_{\mathrm{ss}}^{2}-\left[\mathrm{g}_{\mathrm{e}}+\alpha \beta\left(\psi \mathrm{E}_{\mathrm{ext}}+\psi \mathrm{E}_{0}-\hat{\mathrm{E}}_{0}\right)\right] \mathrm{E}_{\mathrm{ss}}} \\
-\alpha \beta\left(\hat{\mathrm{E}}_{0}-\psi \mathrm{E}_{0}\right) \mathrm{E}_{\mathrm{ext}}=0
\end{array}
$$

The roots of this second-order polynomial are given by (10).

Computation and evaluation of the Jacobian of (8) and (9) in steady state

$$
\begin{aligned}
& \dot{\mathrm{E}}(\mathrm{t})=\mathrm{g}_{\mathrm{e}} \mathrm{E}(\mathrm{t})\left(1-\frac{\mathrm{E}(\mathrm{t})}{\mathrm{E}_{\max }}\right)-\beta\left\{\hat{\mathrm{E}}_{0}-\psi\left[\mathrm{E}_{0}-\mathrm{E}(\mathrm{t})\right]\right\} \mathrm{P}(\mathrm{t}) \\
& \dot{\mathrm{P}}(\mathrm{t})=\mathrm{g}_{\mathrm{p}} \mathrm{P}(\mathrm{t})\left(1-\frac{\mathrm{P}(\mathrm{t})}{\alpha\left[\mathrm{E}(\mathrm{t})-\mathrm{E}_{\text {ext }}\right]}\right) .
\end{aligned}
$$

In steady-state,

$$
\mathrm{P}=\frac{\mathrm{g}_{\mathrm{e}} \mathrm{E}\left(1-\mathrm{E} / \mathrm{E}_{\max }\right)}{\beta\left[\hat{\mathrm{E}}_{0}-\psi\left(\mathrm{E}_{0}-\mathrm{E}\right)\right]}
$$

and

$$
\mathrm{P}=\alpha\left[\mathrm{E}-\mathrm{E}_{\mathrm{ext}}\right] .
$$

The Jacobian

$$
\mathrm{J}=\left[\begin{array}{ll}
\frac{\partial \dot{\mathrm{E}}}{\partial \mathrm{E}} & \frac{\partial \dot{\mathrm{E}}}{\partial \mathrm{P}} \\
\frac{\partial \dot{\mathrm{P}}}{\partial \mathrm{E}} & \frac{\partial \dot{\mathrm{P}}}{\partial \mathrm{P}}
\end{array}\right]=\left[\begin{array}{cc}
{\left[\mathrm{g}_{\mathrm{e}}\left(1-2 \mathrm{E} / \mathrm{E}_{\max }\right)-\beta \psi \mathrm{P}\right]} & -\beta\left[\hat{\mathrm{E}}_{0}-\psi\left(\mathrm{E}_{0}-\mathrm{E}\right)\right] \\
\mathrm{g}_{\mathrm{p}} \mathrm{P}^{2} /\left\{\alpha\left[\mathrm{E}-\mathrm{E}_{\mathrm{ext}}\right]^{2}\right\} & \mathrm{g}_{\mathrm{p}}\left\{1-2 \mathrm{P} /\left[\alpha\left(\mathrm{E}-\mathrm{E}_{\mathrm{ext}}\right)\right]\right\}
\end{array}\right]
$$


Recalling that in steady state $\mathrm{P}=\frac{\mathrm{g}_{\mathrm{e}} \mathrm{E}\left(1-\mathrm{E} / \mathrm{E}_{\max }\right)}{\beta\left[\hat{\mathrm{E}}_{0}-\psi\left(\mathrm{E}_{0}-\mathrm{E}\right)\right]}$ holds,

$\mathrm{J}=\left[\begin{array}{lc}{\left[\mathrm{g}_{\mathrm{e}}\left(1-2 \mathrm{E}^{\mathrm{ss}} / \mathrm{E}_{\max }\right)-\beta \psi \alpha\left(\mathrm{E}^{\mathrm{ss}}-\mathrm{E}_{\mathrm{ext}}\right)\right]} & -\beta\left[\hat{\mathrm{E}}_{0}-\psi\left(\mathrm{E}_{0}-\mathrm{E}^{\mathrm{ss}}\right)\right] \\ \alpha \mathrm{g}_{\mathrm{p}} & -\mathrm{g}_{\mathrm{p}}\end{array}\right]$

In further recalling that in steady state $\mathrm{P}=\alpha\left[\mathrm{E}-\mathrm{E}_{\text {ext }}\right]$ holds,

$J=\left[\begin{array}{lc}{\left[g_{\mathrm{e}}\left(1-2 \mathrm{E}^{\mathrm{ss}} / \mathrm{E}_{\max }\right)-\beta \psi \alpha\left(\mathrm{E}^{\mathrm{ss}}-\mathrm{E}_{\mathrm{ext}}\right)\right]} & -\frac{\mathrm{g}_{\mathrm{e}} \mathrm{E}\left(1-\mathrm{E} / \mathrm{E}_{\max }\right)}{\alpha\left(\mathrm{E}^{\mathrm{ss}}-\mathrm{E}_{\mathrm{ext}}\right)} \\ \alpha \mathrm{g}_{\mathrm{p}} & -\mathrm{g}_{\mathrm{p}}\end{array}\right]$. 